\title{
iglesia de Blumenau
}

H. STRIFFLER, Dipl. ing., arquitecto

$148 \cdot 95$

\section{simopsis}

Consta, esencialmente, de: capilla propiamente dicha y zona de entrada, desde la que se accede a la sacristía, cuarto de caefacción, y se sube al coro.

Al entrar en la nave, la sinceridad formal y de los materiales empleados actúan poderosamente sobre el visitante, y le preparan para su encuentro espiritual con Dios.

Toda ella está construida con hormigón material como la plástica de su forma, sorprenden por su agradable efecto.
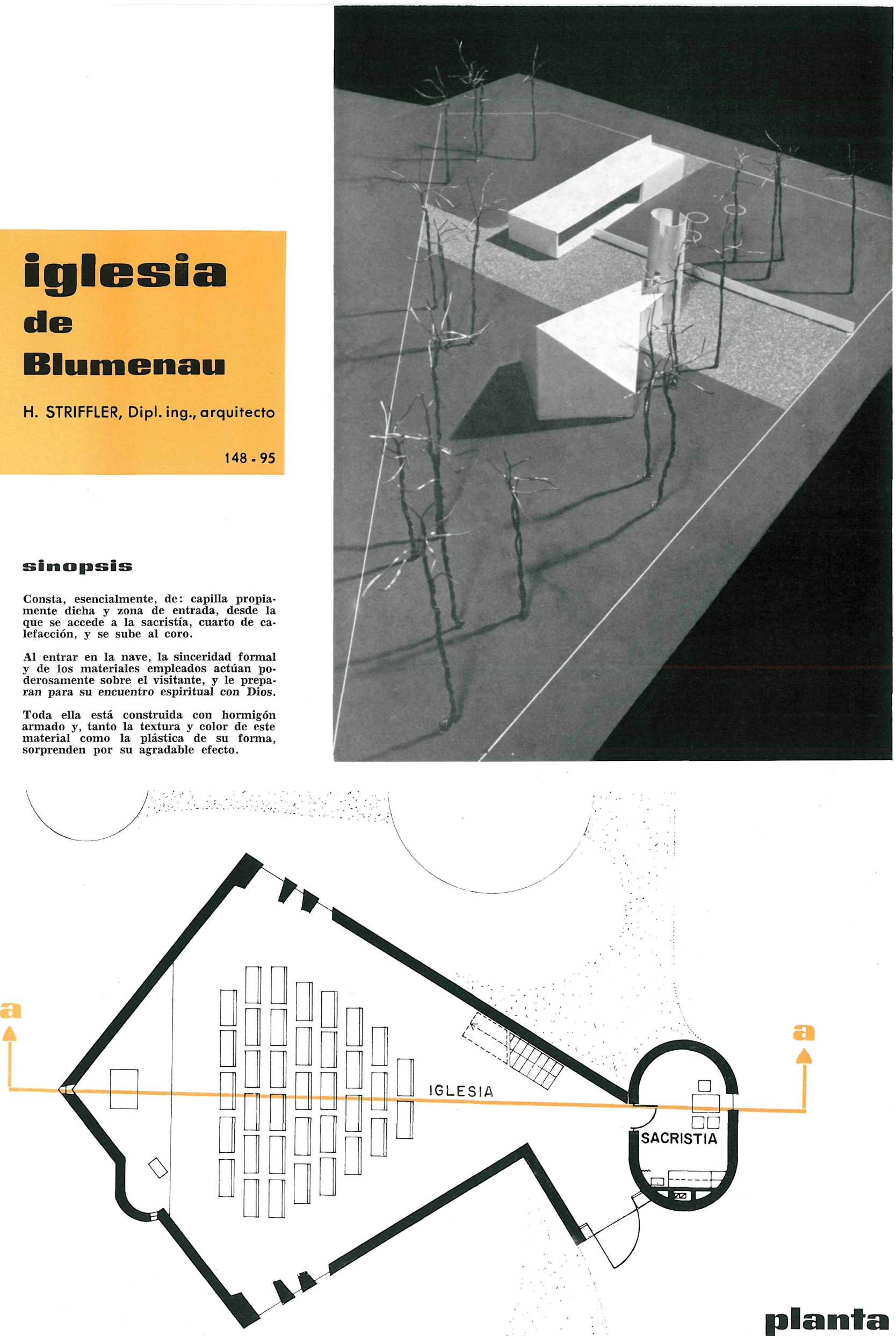

planta 


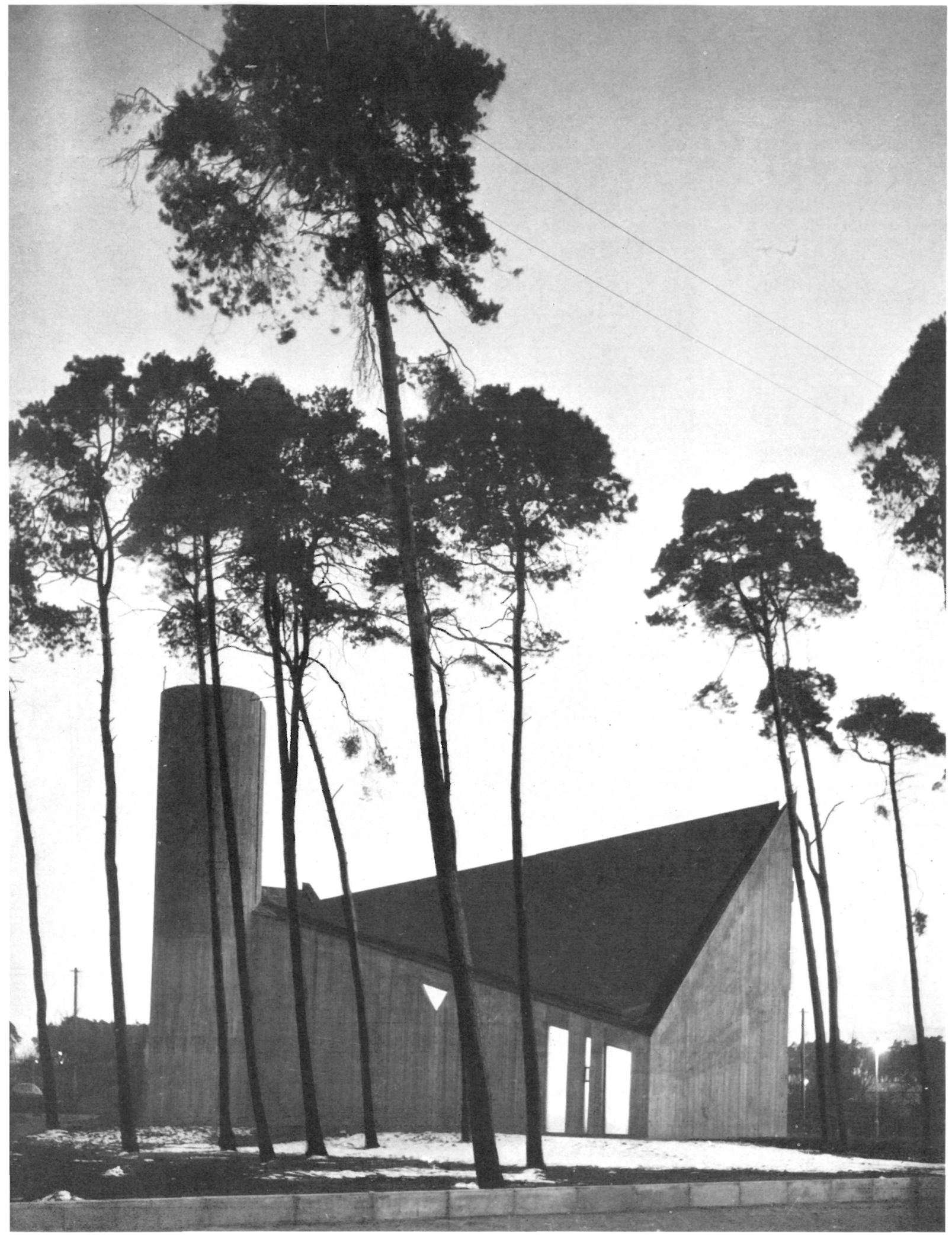

La iglesia está constituida, esencialmente, por: una capilla propiamente dicha, y una zona de entrada-desde la que se accede a la sacristía, cuarto de calefacción y se sube al coro-.

Los muros de cerramiento de la sacristía forman el cuerpo inferior de la torre-campanario, cuya parte superior queda abierta.

Tanto los muros como la cubierta, han sido construidos en hormigón armado. Esta última va protegida por un aislamiento térmico, y aparece acabada en su capa superior por una lámina de cobre. 
La puerta principal ha sido ejecutada a base de chapa de acero, lo mismo que el púlpito; la galería superior, los bancos de la capilla, y la mesa del altar son de madera de pino.

Los huecos exteriores no tienen cerco, ya que los pa neles de cristal, de $35 \mathrm{~mm}$ de espesor, que constituyen el cerramiento, van encajados dentro de las ranuras previamente dejadas en el hormigón. caliente, y su pavimento está formado por grandes losas, de hormigón armado y pulimentado, apoyadas en puntos de modo que dejen un espacio hueco por el que circula dicho aire caliente.

«Dios es espíritu, y los que le adoran tienen que hacerlo en el espíritu y en la verdad».
La nave dispone de instalación de calefacción, por aire
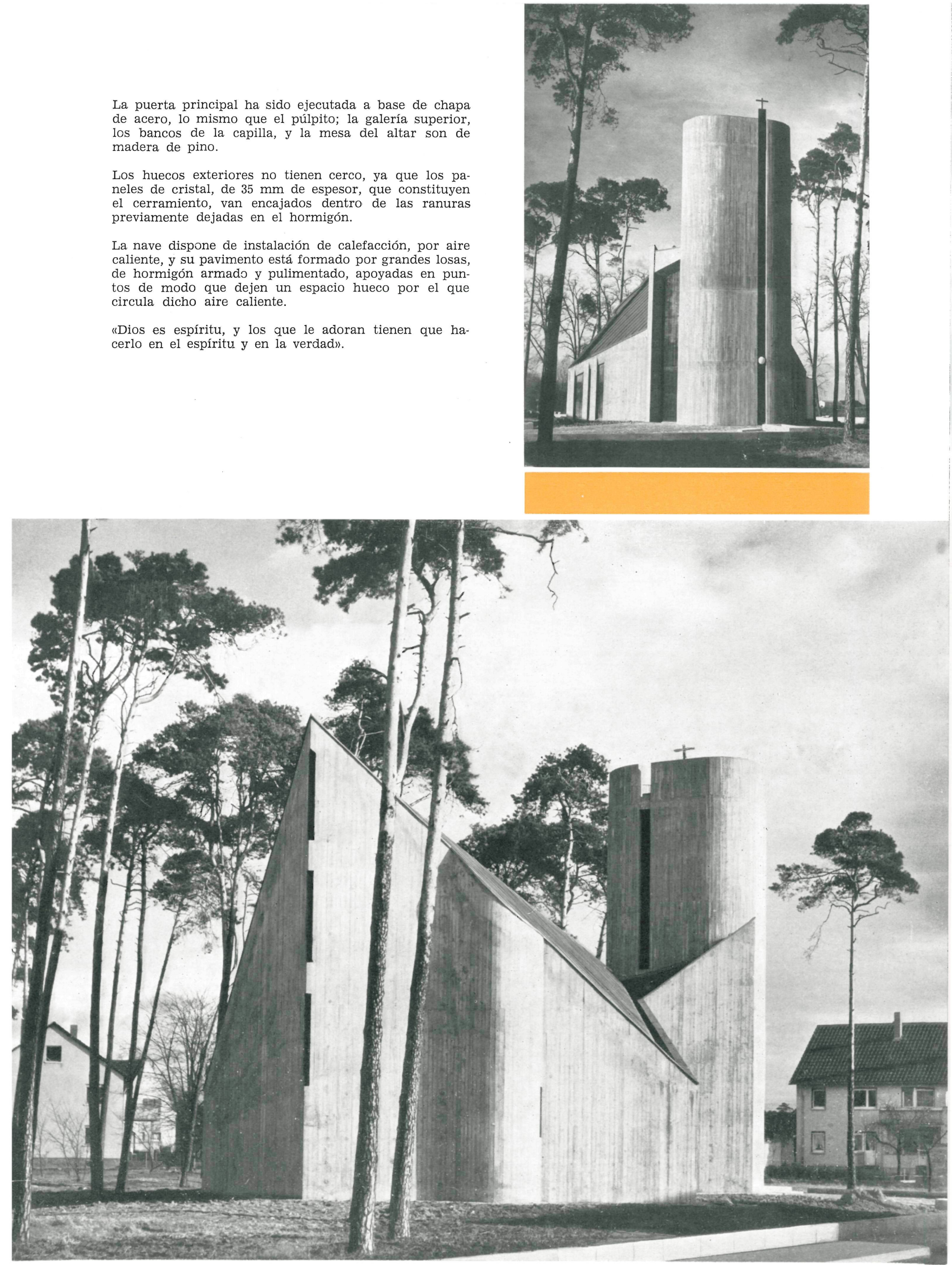


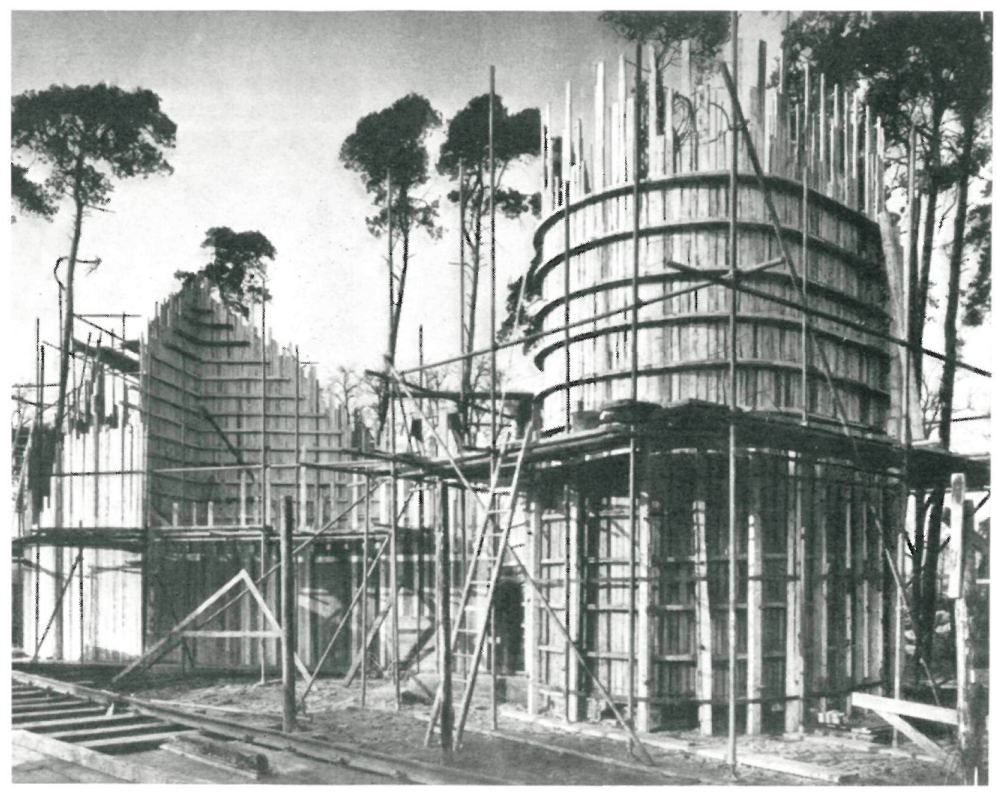

He aquí el pensamiento fundamental que guió al arquitecto en la concepción de su obra. Fiel a esta premisa, organizó la planta en forma que quedasen distinguidas claramente las zonas dedicadas a los sacramentos y a los feligreses; y dispuso que la cubierta se extendiese libremente y con líneas dinámicas sobre este espacio.

Entendió que las paredes debían ser lisas y grandes para mostrar a los hombres que también la sobriedad de la vida diaria pertenece a Dios.

Del material empleado preponderantemente-el hormigón-, el arquitecto dice: "Tenemos que aprender a moldear el hormigón para nuestras iglesias, para que los hombres sientan que con él no solamente se pueden construir puentes, muros, grandes edificios y protecciones antiaéreas, sino que este material sirve también para levantar la Casa de Dios.»

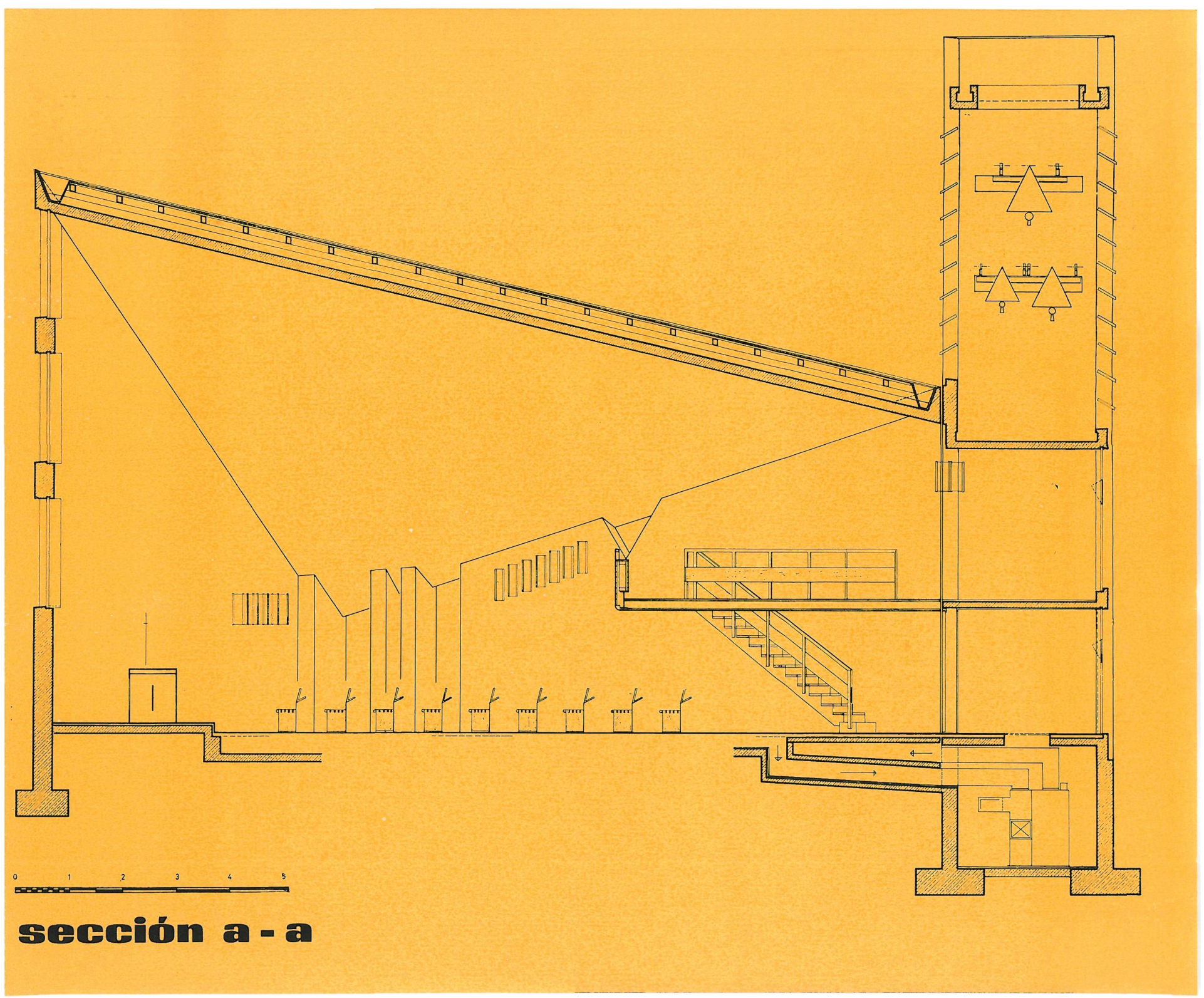



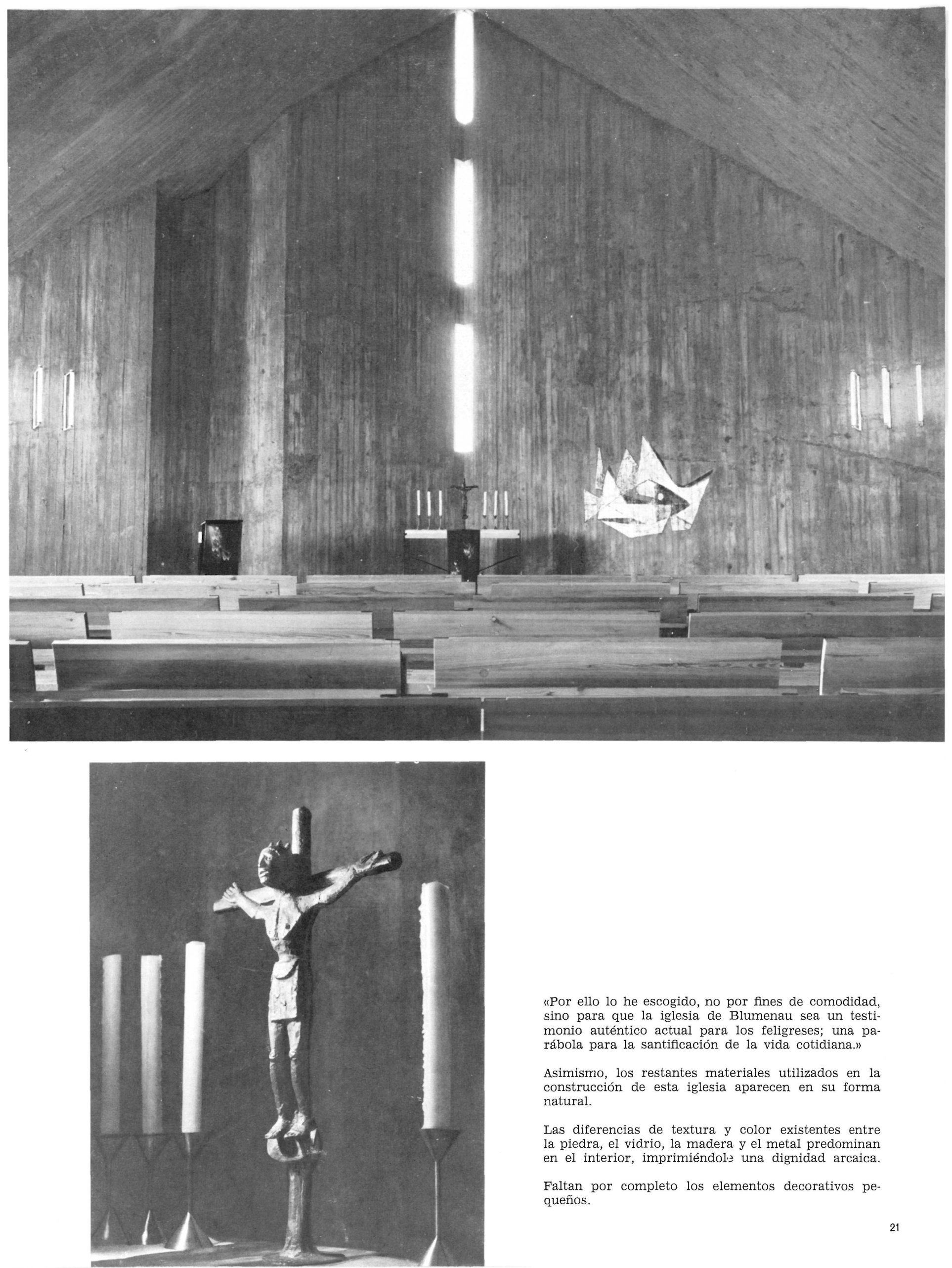

«Por ello lo he escogido, no por fines de comodidad, sino para que la iglesia de Blumenau sea un testimonio auténtico actual para los feligreses; una parábola para la santificación de la vida cotidiana."

Asimismo, los restantes materiales utilizados en la construcción de esta iglesia aparecen en su forma natural

Las diferencias de textura y color existentes entre la piedra, el vidrio, la madera y el metal predominan en el interior, imprimiendoles una dignidad arcaica.

Faltan por completo los elementos decorativos pequeños. 


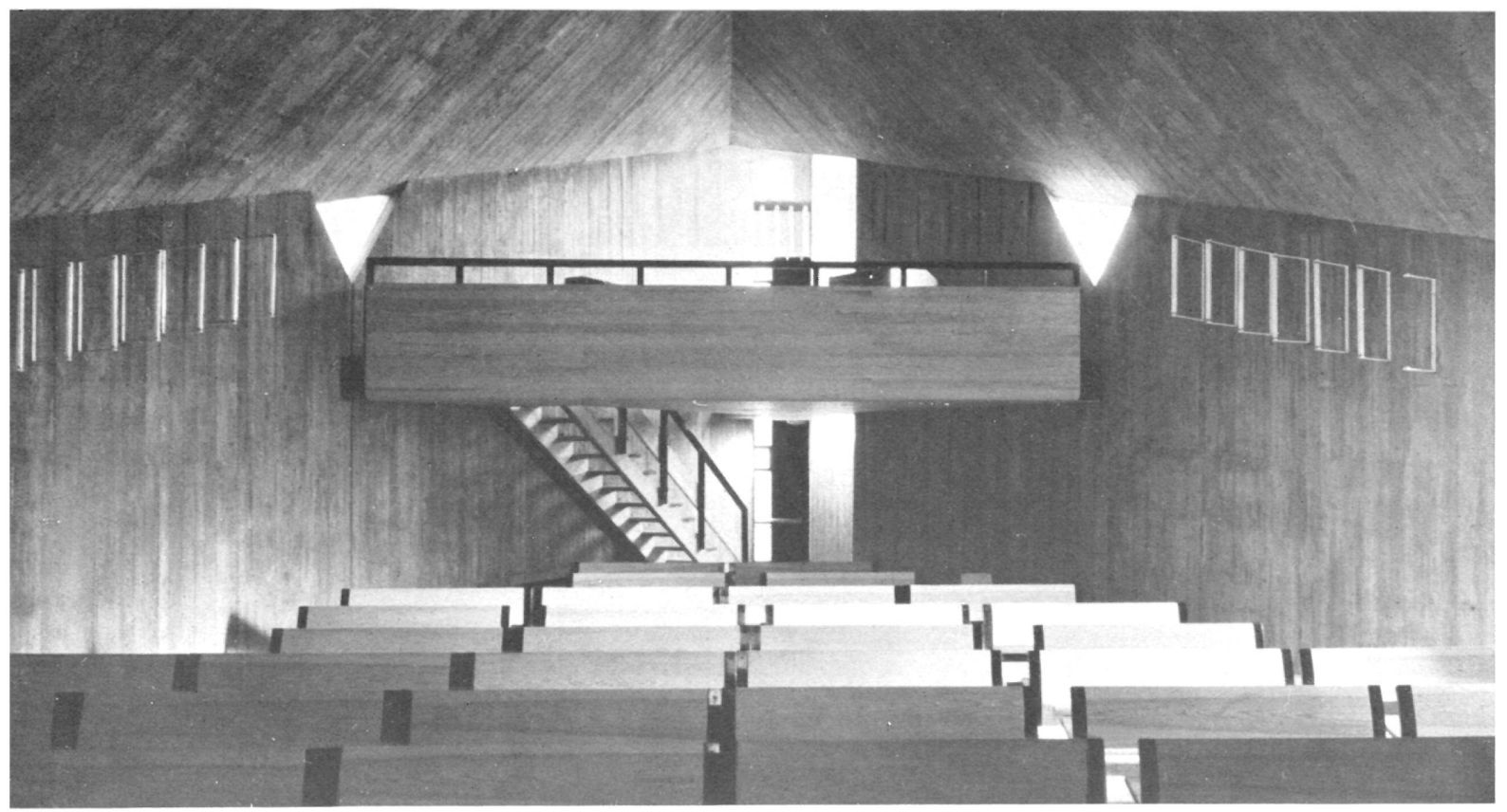

Fotos: ROBERT HAUSSER

Al entrar en el interior se recibe una sensación de silencio, recogimiento y alegría íntima; la sinceridad de las cosas y materiales que le rodean produce un efecto liberador sobre el visitante y le prepara para su encuentro espiritual con Dios.
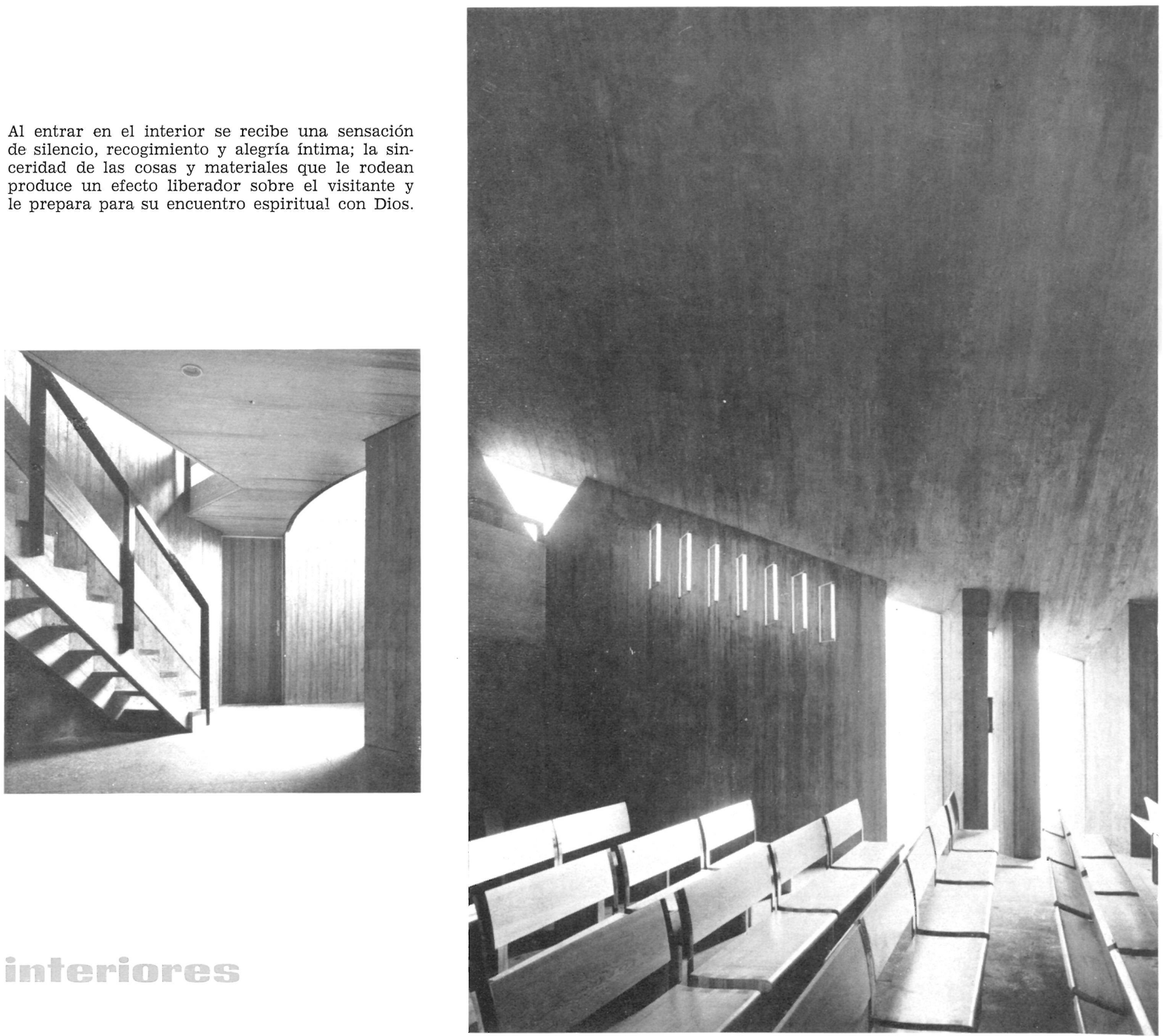


\section{Eglise de Blumencu}

H. Striffler, ingénieur diplômé, Architecte.

Cette église se compose essentiellement de la chapelle proprement dite et de la zone d'entrée, qui permet l'accès à la trimune, ̀̀ la sacristie et à la salle de chauffage.

Dès l'entrée de la nef, la franche simplicité des matériaux employés agit fortement sur le visiteur et la prépare ̀̀ la recontre spirituelle avec Dieu.

Construite entièrement en béton armé, autant la texture et la couleur de ce matériau que la plasticité de sa forme, surprennent agréablement.

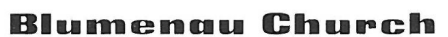

H. Striffler, Dipl. engineer, Architect.

This project involves the chapel itself, and the entrance. From the latter there is direct access to the sacristy, the heating room and the choir.

The visitor is strongly moved by the formal sincerity and the effectiveness of the materials employed in the construction of the chapel: he is placed in the most favourable mood to seek communication with his Creator.

The structure is wholly reinforced concrete, and it is surprising to find how pleasant is both the texture, colour and external plasticity of this material when employed skillfully.

\section{Kinche in Blumemen}

H. Striffler, Diplomingenieur, Architekt.

Sie besteht im Wesentlichen aus der eigentlichen Kapelle und dem Eingang, von dem aus man zur Sakristei, zum Heizungsraum und zum Chor gelangt.

Beim Eintritt in das Kirchenschiff wird der Besucher besonders von der Einfachheit des verwendeten Materials stark beeindruckt, die ihn sozusagen geistig für das Gegenüberstehen mit Gott vorbereitet.

Wie Kirche besteht aus Stahlbeton und sowohl die Textur als auch die Farbe dieses Materials überraschen aufgrund ihrer angenehmen Wirkung. 